\title{
Los retos pedagógicos de enseñar y aprender con TIC en el nivel Superior
}

\section{Yanina Mariela Merelas ${ }^{1}$}

\section{Aporte de Estudiante}

Posgrado

Resumen: En la actualidad, las TIC se han convertido en una herramienta productora de conocimiento, socialización, educación y de acceso a la información. Con la incorporación de las TIC a la enseñanza en todos sus niveles, se ha promovido un cambio no solo en las formas de enseñar y aprender: se han trasformado todas las prácticas institucionales.

La educación tiene la responsabilidad de generar profesionales con capacidad de desenvolverse en entornos complejos y cambiantes que demanda continuamente nuevos aprendizajes debido a la rapidez con la que se desenvuelve la sociedad del conocimiento y la información. La dimensión tecnológica trasciende la existencia humana y es por ello que surge la necesidad de crear nuevas formas de alfabetización que nos permitan poder comprenderla y materializarla, y que promuevan el desarrollo de la capacidad de participar y actuar en forma autónoma y crítica en la sociedad. A partir de esto, es necesario reflexionar sobre la complejidad de las prácticas educativas en el nivel superior y en la construcción de criterios pedagógicos capaces de sustentar su desarrollo, permitiendo dar respuesta a los problemas actuales que el nivel atraviesa.

El presente desarrollo pretendemos esclarecer la necesidad de la incorporación de las TIC en la enseñanza dentro todos los niveles educativos (especialmente en el nivel superior) y analizar cuáles son los retos pedagógicos que exigen la incorporación de las mismas en nuestras propuestas didácticas.

\section{1) Los retos pedagógicos de enseñar y aprender con TIC en el nivel superior}

El mundo está experimentando una revolución tecnológica de primer orden, centrada en torno a las tecnologías de la información y la comunicación (TIC) y la ingeniería genética. Internet es, a la vez, el epítome y el medio más poderoso de esta revolución. Bajo el impulso de nuevas tecnologías y de formas flexibles de organización y dirección, estamos asistiendo a la formación de una nueva economía,

\footnotetext{
${ }^{1}$ Lic. y Prof. en Ciencias de la Educación (UNLZ), Diplomada Superior en Educación y Nuevas tecnologías (FLACSO), Especialista en Educación y Nuevas tecnologías (FLACSO), estudiante de la Especialización en Didáctica y Currículum (UNLZ) y de la Maestría en Currículum (UNLZ).

Correo electrónico: merelasyanina@gmail.com
} 
caracterizada por el progresivo incremento de la productividad y la competencia global. Las perspectivas indican que este dinamismo económico continuará en economías claves, así como en áreas escogidas del mundo en vías de desarrollo (Castells, 2002, p. 91).

En la era de la conectividad, las personas, las instituciones, los grupos y las organizaciones hacen de las plataformas digitales un lugar de pertenencia: habitan la web desarrollando códigos de comunicación y comportamiento totalmente renovados. Estas transformaciones en las formas de actuar, pensar, sentir y comunicarse, impactan directamente en el campo educativo.

Como actores institucionales tenemos la responsabilidad de formar sujetos con la capacidad de participar y actuar en forma autónoma y crítica dentro de la sociedad, es por ello que debemos re-pensar nuestras prácticas de enseñanza a partir del siguiente interrogante: ¿Cómo enseñar y aprender con TIC?

\section{2) ¿Qué ocurre con la práctica docente?}

La incorporación de las TIC en los procesos de enseñanza y aprendizaje, ha producido cambios en el ejercicio de la docencia y en las competencias que los profesores debemos manejar para el tratamiento de los contenidos curriculares.

Resulta imprescindible desarrollar métodos pedagógicos que integren las TIC en nuestra actividad áulica. Los docentes necesitamos estar familiarizados con el uso de las herramientas tecnológicas y tener en claro con qué criterio pedagógico utilizaremos determinado recurso. Esta decisión, es lo que realmente le otorga sentido a la integración de las TIC en nuestras prácticas: la simple incorporación de estas herramientas y recursos, no conducen a una verdadera innovación pedagógica.

Las nuevas tecnologías se diferencian de las tradicionales en la posibilidad de construir nuevos entornos comunicativos y expresivos, que proporcionan la posibilidad de desarrollar nuevas experiencias formativas, expresivas y educativas.

Debemos tener presente que enseñar y aprender en una realidad atravesada por la cultura digital requiere docentes preparados, que puedan repensar sus prácticas e incorporar nuevas estrategias de organización y gestión del conocimiento en el aula. Para lograr este objetivo, es importante familiarizarnos con las nuevas herramientas de búsqueda, organización y gestión de contenidos que hoy se encuentran a nuestro alcance.

Al momento de planificar nuestras clases, resulta fundamental pensar en los materiales que utilizaremos para llevar adelante cada una de ellas. Utilizamos desde guías de preguntas, hasta presentaciones en power point, imágenes, gráficos, etc. La realidad 
indica que no siempre resulta adecuado desarrollar el método de la clase magistral (donde el docente sólo expone, y los alumnos que ofician de receptores, sólo se remiten a escuchar al docente que se encuentra frente al curso), motivo por el cual también resulta necesario y atrapante llevar a cabo modalidades como el roleplay y método de casos, con el objetivo de potenciar nuestra propuesta didáctica. Sin embargo, en los últimos años los avances tecnológicos han contribuido a la creación de diversos soportes y formatos que han multiplicado las posibilidades de usar y crear recursos dentro del aula.

Los distintos materiales didácticos que el docente elabore para el desarrollo de cada clase, serán el punto de partida de su propuesta didáctica. La elección de los distintos recursos es una decisión fundamental, ya que los mismos presentan de un modo determinado aquello que se quiere enseñar. Esta presentación (su estructura semántica, los lenguajes que utiliza, las preguntas que propone, su diseño, etc.) da forma a aquello que se quiere transmitir y por lo tanto, es parte del contenido.

\section{3) El uso de las TIC en el aula}

La incorporación de recursos y herramientas tecnológicas en el ámbito educativo permite ampliar y enriquecer el abanico de propuestas didácticas. Los materiales audiovisuales posibilitan nuevos lenguajes y favorecen la creación de entornos que potencian nuestras propuestas.

Al añadir múltiples recursos en las actividades áulicas, se diversifican los modos de construcción de significados: cada alumno se apoderará de los contenidos curriculares de acuerdo a su estilo cognitivo de aprendizaje. Es por ello que podemos utilizar diversas formas de representación para favorecer las habilidades cognitivas de nuestros alumnos: Esto es, múltiples y variadas formas de acceder al conocimiento.

Las TIC en el aula convierten al sujeto en actor y protagonista de su propio aprendizaje.

\section{1 La incorporación de las TIC en las prácticas de enseñanza del Nivel}

\section{Superior}

Cada uno tiene en su interior un "modelo" de docente que debe ser examinado, para saber realmente cuál es el que reflejamos nosotros mismos. Podemos adecuar nuestras estrategias de intervención como docentes a varias posibilidades. En la actualidad, existe una gran cantidad de recursos tecnológicos presentes en el nivel superior, sin embargo, las prácticas de enseñanza se continúan estructurando en los recursos clásicos: pizarrón, apuntes y otros materiales impresos. Es fundamental que los 
futuros profesionales comprendan y manejen los alcances de la informática y la comunicación, sus exigencias en los procesos del pensamiento y sus formas de trabajo. Es por ello, y en respuesta a las necesidades actuales, que proponemos nuevas alfabetizaciones basadas en las Tecnologías de la Información y la Comunicación.

Este cambio de paradigma en las formas de enseñanza y aprendizaje permite pensar en nuevas y posibles aplicaciones educativas. Las redes de telecomunicaciones ofrecen un gran potencial para la educación: el uso del correo electrónico, la transferencia de archivos, la búsqueda de información y la investigación, el intercambio de experiencias, las teleconferencias, etc., producen diferentes tipos de interacciones humanas.

Las clases presenciales que se desarrollan dentro del aula, necesitan de nuevos espacios que complementen el conocimiento mediante el uso de medios tecnológicos entre estudiantes y docentes (concepto de aula invertida). Esta nueva dinámica de intercambio con el alumno, implica la utilización de las TIC para proporcionar a los estudiantes, recursos por fuera del horario de clase.

La diversidad de escenarios, contextos y tendencias en la educación actual, imponen nuevos roles al proceso formativo, los que implican retos para el profesional del futuro, las instituciones y agentes encargados de su formación.

\section{Conclusión}

La educación en toda su historia ha evolucionado significativamente, prueba de ello es que la modalidad de clase magistral no es la única que los docentes elegimos para llevar adelante en el trabajo cotidiano, por el contrario, consideramos que hoy resulta imprescindible la incorporación de nuevas tecnologías en el método de enseñanza (tales como la utilización de power point, gráficos, realización de teleconferencias, entre otros variados medios audiovisuales disponibles hoy en día). No podemos dejar de mencionar otros medios que también se encuentran en franco ascenso o crecimiento, tal es el caso de "grupos" que se conforman dentro de la red social Facebook, como así también los "grupos" conformados -tanto por alumnos, como por docentes- dentro de la aplicación WhatsApp, disponible en casi todos los teléfonos móviles de la república, y finalmente los portales web. El objeto de los mismos, es que la interacción docente - alumno / alumno docente, no culmine al finalizar la clase, sino que prosiga más allá.

Es por ese motivo, que creemos totalmente necesario aggionarnos a los tiempos que corren, incorporando a las nuevas tecnologías en ésta noble tarea, promoviendo a construir nuevas alfabetizaciones basadas en las Tecnologías de la Información y la Comunicación. 


\section{Referencia}

Castells, M. (2009). Comunicación y poder. Traducción de María Hernández Díaz. Madrid: Alianza Editorial. 